\title{
THE ANTHROPOMETRY OF BODY ACTION*
}

\author{
By Wilfrid Taylor Dempster \\ Department of Anatomy, University of Michigan, Ann Arbor, Mich.
}

Conventional anthropometry of the adult has been limited largely to measurements that may be made with the anthropometer, the tape measure, and the calipers. The dimensions are linear, and they relate to the body surfaceheights of body landmarks, widths, circumferences, and spans between surface points. To be duplicable, the measurements must be made in the same manner on different individuals, and the subjects must assume a stereotyped static posture, usually standing, during measurement. Supplementary and equally stereotyped postures such as sitting, supine, arms outstretched, etc., may also be used. The measurements, of course, allow comparisons between individuals and between population groups. They provide information on the relative magnitude and variability of individuals, but they are in no way functional measurements.

If a dynamic anthropometry is to be developed that can cope with problems of movement and postural change, new methods must be sought, and the parameters of measurement must be extended to include angles, velocity, acceleration, rhythmic patterns, space envelopes, and force. Body activity is infinitely variable, and it is essential that there be a theoretical framework so that relevant and secondary features may be evaluated correctly. Similarly, it is important that the conditioning factors and inbuilt limitations of the body machinery be also understood. Simplifications and abstract concepts are necessary, but it is important that these should not be oversimplified relative to the specific problem at hand.

Studies based on dynamic measurements should contribute to human comfort, efficiency, convenience, and safety. One may envision the application of work-space information to the industrial worker, to the school room, to vehicles and machinery, and to military problems. There should be contributions to furniture design and to the architecture of such work spaces as kitchens and bathrooms. In addition, a better understanding of dynamic actions of the body mechanism should provide help in the coaching of athletic performance, in the design of work clothing, including shoes and gloves, in personnel selection, and in the designing of prostheses.

Braune and Fischer ${ }^{6}$ were pioneers in this field, and more recent work has been done by Lay and Fisher, ${ }^{26}$ Hooton, ${ }^{21}$ Randall et al. ${ }^{, 1} \mathrm{King},{ }^{22}$ Chapanis et al. ${ }^{8}$ Smith and his group, ${ }^{33} \mathrm{McF}$ arland et al. ${ }^{28}$ and Dempster. ${ }^{11}$

\section{Bone Functions in Body Mechanics}

Bones have many functions: they are reservoirs of calcium, phosphorus, and carbonate; they house the bone marrow, which produces the red blood cells, leucocytes, and platelets of the blood; they provide processes and expansions

\footnotetext{
* A study conducted under contracts with the Wright Air Development Center (Section of Anthropometry) Wright Patterson Air Force Base, Dayton, Ohio, and with the United States Office of Naval Research, Washington, D.C.
} 
for muscle attachment and leverage; they grow and mature, and their form is responsive to diet, to hormones, and to persistent and intermittent forces. These features, however, may be ignored here as irrelevant to the mechanical essential of rigidity. Forces may be transmitted along or across the rigid substance of bone. Bone has a tensile strength and modulus of elasticity in tension like walnut or hickory wood. It is as strong as concrete in compression, and its compressive modulus of elasticity is comparable also. ${ }^{12}$

Within the range of ordinary behavior, bone may be considered as a competent rigid material. It spans the articulations and separates the joints by fixed distances. Moreover, the ends of the bones, where adjacent bones attach, are molded into specific configurations (FIGURE 1) that permit unique types and directions of movement.

Bones form the essential levers of the body system. Although tensile or compressive stresses are transmitted along the substance of the bony material, the effective levers for rotatory actions follow straight lines between one joint center and the next in sequence. In the femur or radius, such straight lines between joint centers actually fall in part outside the limits of the curving shapes of the bony substance. Where both ends of a bone have rounded (i.e., convex) articulations, the line goes from center to center within the length of the bone. In certain locations such as the forearm and leg, the lines span from a joint center located in the more proximal bone, i.e., in the humeral or femoral condyles, through the whole bony support of the segment in question to a center in the adjacent distal bone in the hand or foot, that is, through a chain of three bones. These spanning distances between adjacent joint centers are the functional equivalent of the "links" of the engineer.

\section{The Body Link System}

The engineer commonly regards links as parts of a two-dimensional system that might be diagrammed on paper. The articulating parts overlap and are joined by pins, which act as axes of rotation (sliding-plane and helical joints sometimes found in machinery may be ignored here as special classes that are of little concern in the body system). The link is a line of constant length that spans the pin axes. It is a functional dimension dependent upon the rigidity of the material that separates the centers of rotation. The metal parts of a machine per se are not links. A link is merely a line-an abstraction-that may execute only those angular displacements allowed by the joint elements.

In the machinery of the engineer, the links move in relation to a framework, and this framework becomes, in reality, an additional link that interconnects the others. In order to transmit power, the linkages of machinery must form a closed system in which the motions of one link have determinate relations to every other link in the system. The closed system assures that forces are transmitted in positive predetermined ways and in no other. ${ }^{32}$ The study of the relative motions of the links of machinery forms the subject matter of kinematics, a powerful tool for the design and improvement of mechanisms of all types.

In engineering, a background of kinematics gives understanding. It should likewise have value in relation to body motions. 


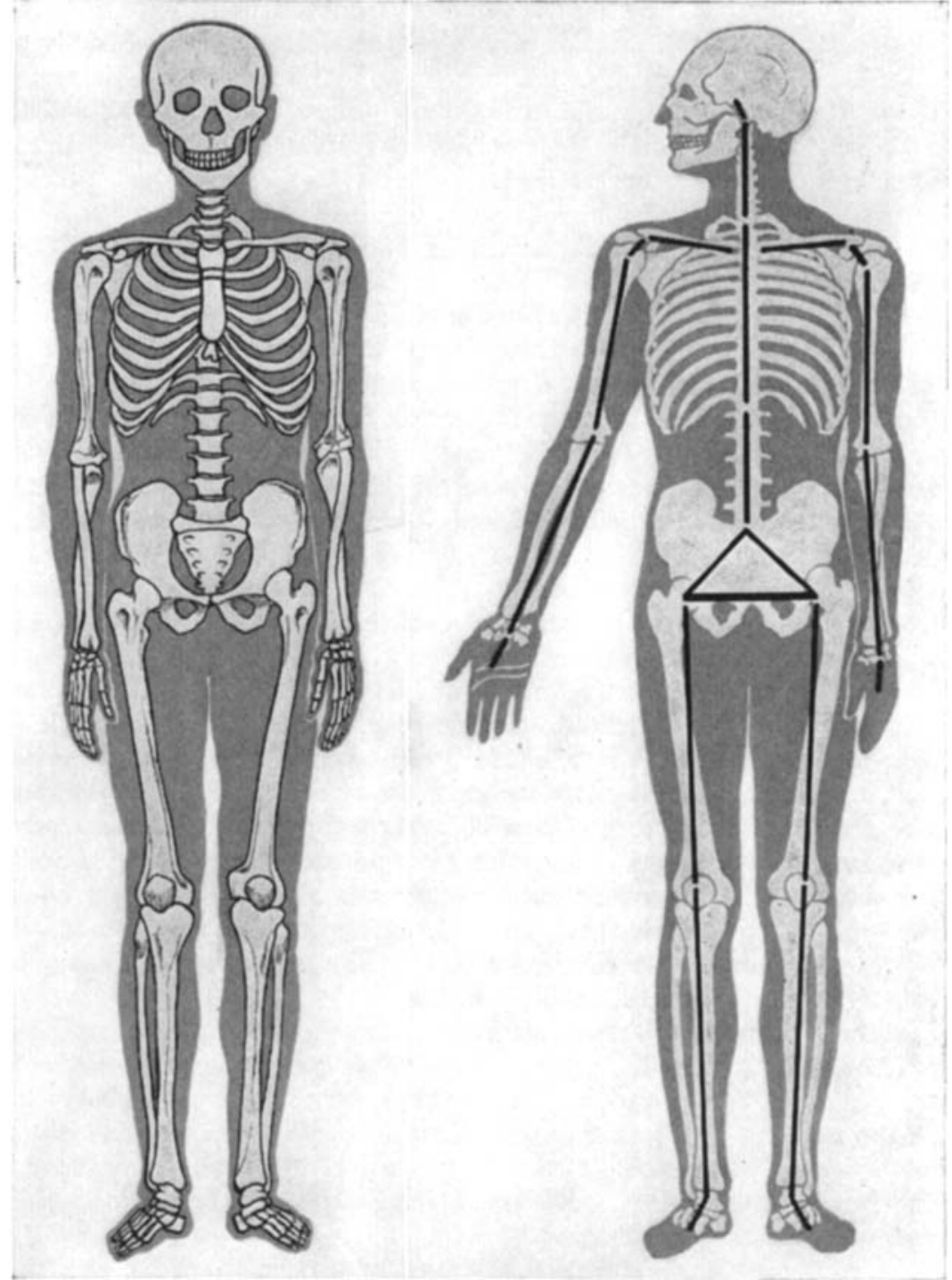

FIGURE 1. Left, human skeleton; right, plan of body links.

The body links rarely overlap, and none is truly pin-centered. In the major limb joints, the contiguous articular surfaces slide relative to one another as the bones rotate about a center in one or the other of the bones. The surfaces, although pressed together by the variable forces of ligaments, muscle, and atmospheric pressure, are ordinarily only partially congruent, since the curvatures are not truly reciprocal. Nevertheless, the areas that do contact as the articular surfaces slide against one another either inhibit or permit free rotatory motions in particular directions. Most of the joints have a freedom for angu- 
lar motion in different directions, and power transmission is quite impossible without the accessory stabilization of joints by muscular action. Strictly predictable, determinate motions of the linkages as found in closed-chain systems are found at very few joints, viz., radio-humero-ulnar, carpal, tarsal, and thoracic joints. The open-chain (indeterminate) system, as Fischer ${ }^{18}$ indicated, predominates in the body mechanism.

Because of the basic differences between the links of the engineer and those of the body system, certain characteristics of the latter should be outlined. The body link is the straight axial line or core line that extends through a body segment. Its integrity depends upon the rigid substance of the bone, and it terminates in axes about which the adjacent links rotate. The skeletal elements may be reduced to produce a stick figure like that of FIGURE 1 . The anatomical specializations of bones for muscle attachment and joint articulations, important as they are for body functioning, may be ignored in considerations of simple link motions. The bone may flare out or bend away from the core line between adjacent joint centers. The femur, for instance, has its eccentric greater trochanter, the scapula its blade, spine, and acromion, and the elbow its projecting olecranon process. These are important for the muscular control of link movements, but they are entirely secondary to the basic kinematic system of the body segments.

The complex structure of the pelvis with its visceral basin, its birth canal, and its wide areas for muscle attachment may be simplified to a single link though, in this instance, it is triangular, with articulations to both the right and left femoral links and to the vertebral chain of links. Although the thorax may be treated as a separate system of linkages for purposes of the study of the respiratory movements, it may, for gross postural purposes, be simplified to the vertebral links (perhaps even treated as a single link) and a buckethandle type of upper sternocostal linkage bridging from the right to the left of the uppermost thoracic vertebra (FIGURE 7). The latter permits linkage connection with the clavicular links of each side.

Since the link concept has pertinence for the analysis of rotatory motions, it should be apparent that the type of analysis anticipated should determine the degree of reduction to be used. In FIGURE 1, certain obvious linkages have not been shown, as for instance finger and toe links, a forearm link between the radius and ulna, separate links between successive vertebrae, and linkages between the ribs and sternum. The remaining links are probably adequate for most purposes of postural analysis.

The system may be diagrammed on paper, or it may be treated as a threedimensional stick figure. On paper, the angular motions of links may be diagrammed with the aid of a pencil compass. The links can be laid out on frameby-frame records from motion pictures of actual subjects or from stroboscopic photographs of body movements. The movements of parts are most easily analyzed as motions in a plane. Links are linear and their angular movements sweep over surfaces. If the latter are curved, or are not in the plane of reference, they may be projected to suitable rectangular coordinates.

Rotations about the longitudinal axes of the segments are permitted in the trunk and at the ball-and-socket joints of the hip and shoulder (glenohumeral 
joint), at the shoulder girdle joints, at the forearm joints, and at the knee. These movements may be important functionally, and they can be analyzed further. In general, however, such movements are less gross than other rotations in the sense that they involve small moments of inertia. To this effect, the forearm (radio-ulnar joint system) may for many purposes be considered as a single link between the elbow and the wrist (FIGURE 1).

\section{A Plan of Body Linkages}

The "link" man of FIGURE 1 is presented as a simplified kinematic system subject to further extensions as required for specific problems. The 25 vertebral links above the sacrum have been reduced to 3 links: cervical, thoracic, and lumbar. The head link articulates with the cervical. The triangular linkage of the pelvis connects with both the lumbar link and the two thigh (or femoral) links. The sternocostal bucket-handle linkage articulates with the clavicular links and these, in turn, with the scapular links. The latter linkage represents a straight line between the mean center of scapula rotation, relative to the clavicle (on the acromioclavicular and coracoclavicular joint system) and the mean center of glenohumeral rotation. Next comes the humeral link, the forearm link, and the hand link. In the lower limb, the chain of links consists of a femoral link, a shank link, and a foot link.

The hand, foot, and head are end links beyond terminal joints. At the hand, the link might be variably referred to as the linkage between the wrist center and a functional contact point at the heel of the hand, the knuckles, the ball of the thumb, or the finger tip. The foot link might span the ankle center and the heel, or the ankle and the ball of the foot or toes, etc. In general, however, where free movements of the end members are concerned, the parts may be regarded as cantilever systems, and the link span may be regarded as the straight-line distance from the terminal joint to the center of gravity of the part.

The center of gravity of the head lies at the midsagittal plane on a line that interconnects points anterior to the tragi of the ears. The head link extends from this point to the occipitocervical junction. The hand link passes from the wrist center to the "V" between the radial longitudinal and proximal transverse palmar creases in line with the third finger. For the foot, the link terminates halfway down along a line from the ankle center to the ball of the foot in the plane of the second toe.

Mean link dimensions may be visualized as beginning and ending in functional joint centers (or centers of gravity of terminal members). Since these end points are not structural landmarks, the link lengths cannot be measured directly on the static subject. The systematic manipulation of joints permits a fair approximation for the location of mean joint-center positions. More elaborate methods for locating joint centers, based upon cadaver joint preparations and involving geometrical techniques (vide infra), measurements of bone dimensions, including articular curvatures and extrapolations for specific bone lengths, are possible (TABLE 1). But these are not truly routine anthropometric procedures. Fortunately, the linear dimensions are less significant than angular measurements of link movement. 
The link figure presents the essentials of the dynamic man. The links are the basic units to which the angular motions of the body parts may be referred in the multiplicity of body postures and motions. A dynamic anthropometry that is not consistent with their functioning cannot claim more than limited empirical value.

\section{Links and Dynamic Aspects of the Body}

The body is predominately an open-chain system of links. The links rotate about joint centers and exhibit a variety of angular positions consistent with the range of motion permitted by the joints before restraining mechanisms impose limits. An open-chain system cannot produce determinate or strictly predictable motions. The end member may have an infinite number of positions relative to the trunk allowed by the cumulative range of the more proximal joints.

There are advantages in such a system. A part may be placed at a variety of point positions in space. Reach becomes a meaningful function, and balancing reflexes become an essential in the antigravity mechanism of postural maintenance. The body is permitted such motions as kicking, walking, throwing, and the use of tools. Muscular action may stabilize certain motions momentarily at one or another of a chain of joints. Such stability allows the body to concentrate the prime motion of other muscles on specific joints and on specific planes of action. By this mechanism, force applications, accurate throwing, the use of tools, writing, and other animal and human activities become possible.

'The fingers of the two hands may be interlocked to interconnect the right and upper limb links; the legs may be crossed for seated stability; the arms may be crossed or placed on the hips. In such actions as these, temporary approximations to closed chains are effected. Between certain of the links concerned, however, there are soft (nonrigid) tissues. These, in turn, are pressed together to a variable extent, so that interposed skin surfaces make a friction contact. Clothing, gloves, or shoes next to the skin surface will more often decrease than increase the friction contact.

Link chains may be cross-connected, as in crossing the knees (viz., pelvis and right and left thighs) or in placing the hand on the same or opposite shoulder. To the extent that these temporary closed chains approximate a triangular linkage, there is a degree of stability imparted even without muscular actions, but this is still approximate because of the interposed soft tissues. The closer the links approximate a closed triagular, or pyramidal, pattern, the less muscles are called upon for stabilizing action at joints. One may recognize many rest positions involving this principle: crossed arms, hands in pockets, or such sitting positions as crossed knees, ankle on opposite knee, elbow on knee, or head in hand. The dog sitting on his haunches and other quadrupeds show different rest positions. As additional joints come into the linkage, the accessory tensions of muscles become more and more important for stability or for directing forces in specific ways.

Temporary closed chains that involve cxtrinsic environmental objects also may be recognized. For instance, the two arms using a pruning shears are 
such a linkage. When a seated person operates a foot pedal, the closed chain involves the shoe sole, the soft tissues of the foot, the foot and limb links, the pelvis, the nonrigid buttock tissues, the seat, the floor, and the pedal. In the operation of machinery by a hand lever, there is a complex linkage involving the machine links, its frame, the floor, and the body links from foot to hand.

These temporary closed chains can be only approximations to determinate systems, since there are nonrigid tissues between certain links. In addition, the variability of possible motions at most of the joints requires muscle actions that vary with the style of neuromuscular control that an individual may employ. The open-chain system of the body insures unpredictability of action. It allows a variety of selective and discriminatory actions in the transmission of forces. The accuracy and power of control is based upon neuromuscular physiology, and psychological factors cannot be excluded.

The links are functional dimensions rather than structural entities. They represent deep-lying relationships of the joints, and the standard anthropometry involving surface landmarks is quite unrelated to them. Angular motions of the links may be studied, and measurements of the space requirements of the tissue-enclosed kinematic system of the body may be devised. The planning of such measurements, however, requires an understanding well beyond structure alone.

\section{Joints in Relation to Link Movement}

Descriptions of the anatomical structure of the joint elements that interconnect the link members are readily available. The configuration of bones and their cartilages at the contacting regions of the joints predetermines the directions in which links may rotate. When muscle tensions or the superimposed weight of the body acts across a joint, the contiguous surfaces are pressed together. The shape of the contact or the ligamentous bindings either allow or eliminate certain types of angular movement. At the elbow, the forearm joints, or the ankle (tibio-talar joint), movements are restricted to specific guided paths of rotation from which there is no deviation.

At the elbow and ankle, the movements are generally referred to as flexionextension movements, but in each instance there is a sequence of slight contingent movements not limited to the sagittal plane. Nevertheless, the movements are guided from instant to instant, and angular movement can continue or reverse along only the guided path provided by the joint structure. In such joints, extraneous movements are prevented by the wedging of the bony configuration, and there is but one degree of freedom for rotational movement allowed. In FIGURE 2, the members of the elbow and forearm joints have but one degree of freedom of motion.

At the wrist, the hand may flex and extend or move at a right angle in abduction or adduction, but free rotation about a longitudinal axis is virtually eliminated. At the knee, both flexion and extension movements and rotational movements of the shank are possible, but lateral movements do not occur except for a limited range where the ligaments are momentarily lax. In each instance, the predominant movements involve two degrees of freedom (FIGURE 2). At the ball-and-socket joints at the hip and shoulder (glenohumeral joint), 


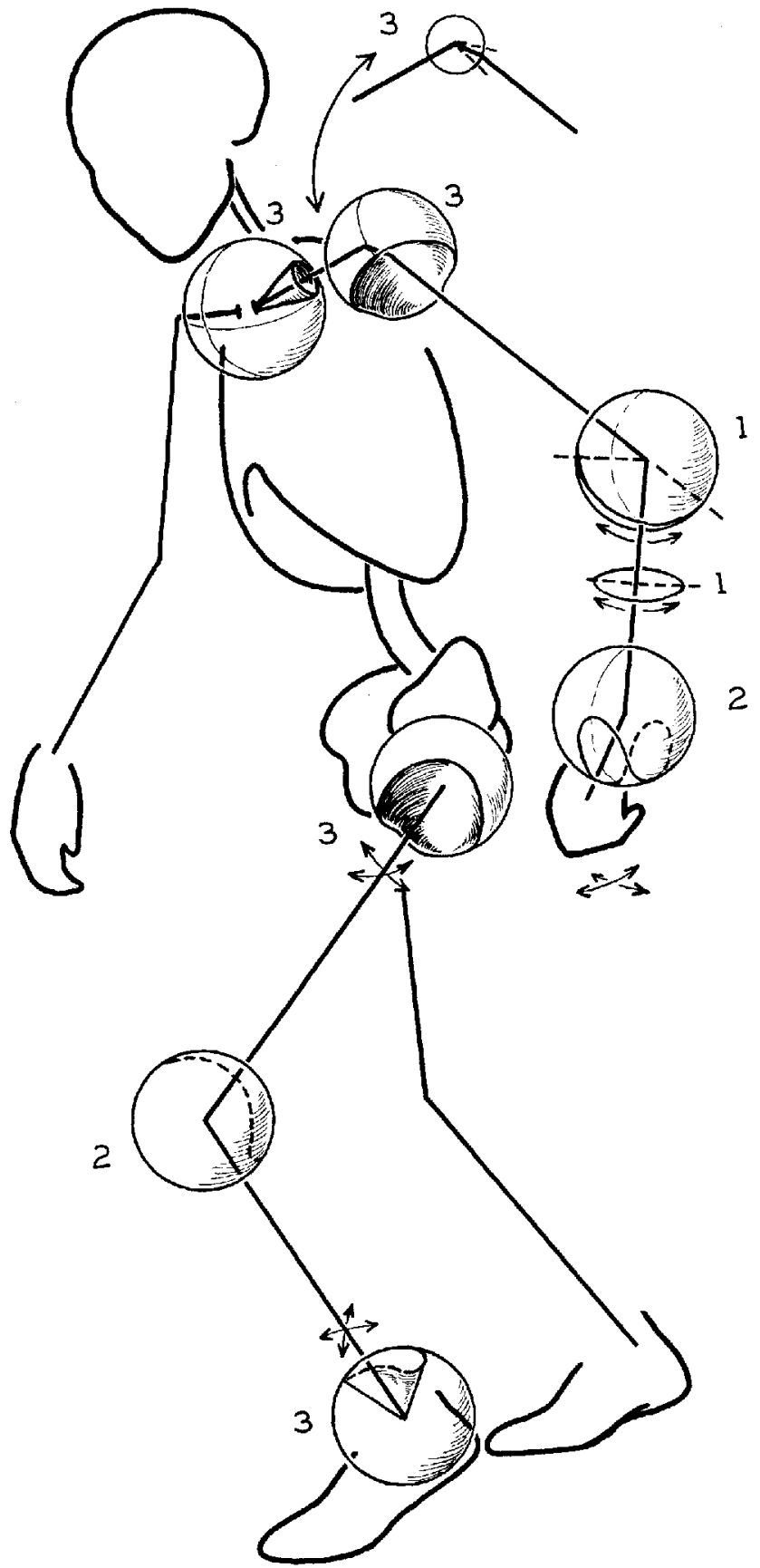

Figure. 2. Link figure with globographic representations of the joint ranges of the cxtremity links. 
there may be inward or outward rotation about the axis of the femoral or humeral link, or there may be movements in the sagittal plane (flexion-extension), or in the transverse plane (abduction-adduction). There is no restriction to the direction of rotation except at the limits of joint range. One may speak of three degrees of freedom of rotational movement. In the subtalar joints of the foot, at the claviscapular joint system (the functional equivalent of the composite coracoclavicular and acromioclavicular joints), and at the sternoclavicular joint, one finds three degrees of freedom at each joint. The analysis might be carried further to the finger and toe joints and to other joints of the trunk, but this is sufficient for illustrative purposes. Fischer ${ }^{18}$ spoke of the degrees of freedom at joints, but this convenient approach has seldom been followed by writers in the United States.

One may note the cumulative pattern of degrees of freedom in a proximodistal sequence: upper limb-3/3/3/1/1/2, and lower limb-3/2/1/3 (FIGURE 2 , however, further simplifies ankle and foot movements in one globe). There are 13 degrees of freedom between the trunk and hand, and 9 degrees between the trunk and foot sole. The sequence in the pattern of motion and in the degree of freedom of succeeding joints differs in the two limbs. Thus the elbow bends on a transverse axis, the forearm rotates on a longitudinal axis, and the wrist has (virtually) no axial rotation. The knee permits bending on a transverse axis and rotation on a longitudinal tibial axis, the ankle axis is approximately transverse, and the lower joints in the foot have rotational axes in several directions. ${ }^{20}$

\section{Range of Joint Movement}

The type and amplitude of movement differs from joint to joint. All movements are rotational rather than translatory, and they are to be measured in degrees or radians. In each instance, ligaments, bony stops (elbow), tissue bulk (knee flexion), or muscle stretch define limits to the range of movement. The functional ranges are based upon anatomical structure, and they are variable from individual to individual. Measurable differences in flexibility are to be expected, due to age, sex, disease, and possibly race and occupation.

There is a literature concerned with the systematizing of terminology and with techniques for measurement for clinical purposes. Instruments and methods have been described, but authors in general have been content with working values rather than with detailed descriptions of movements applicable to specific populations. Exceptions to the general pattern are: Sinelnikoff and Grigorowitsch, ${ }^{35}$ Glanville and Kreezer, ${ }^{19}$ and Dempster, ${ }^{11}$ but even these are incomplete as full coverages of the different joints.

The dynamic anthropometrist should be able, in the future, to provide improved measurement values for the various joints. It would be inadvisable, however, to plan a battery of measurements without a sound functional knowledge based upon experience with cadaver joints.

Various authors have quantitatively studied the range of movement of the principal joints of the limbs on joint-ligament preparations of cadavers. Such data have been presented by: Strasser and Gassman, ${ }^{37}$ Fick, ${ }^{17}$ Shiino, ${ }^{34}$ Braus, ${ }^{7}$ 
Pfuhl, ${ }^{30}$ Steindler, ${ }^{36}$ Mollier, ${ }^{29}$ von Lanz and Wachsmuth, ${ }^{38}$ and Dempster. ${ }^{11}$ Most of the work in the literature applies to the shoulder, hip, and knee joints.

The Albert-Strasser globographic presentation has been commonly used (Albert, ${ }^{2}$ Strasser, and Gassman ${ }^{37}$ ). In this method, one of the bony members of a joint was clamped fast with the approximate functional center of the joint at the center of a large protractor system. The free member was swung to its limits in each direction along the protractor, and the maximum range of movement of a needle point marker on the moving part was recorded. This was repeated also for other meridians at measured angles from the first. These ranges were marked off at appropriate places on a globe provided with a scale of parallels and meridians. Where a joint presented three degrees of freedom of motion, the amplitude of movement along the long axis of the moving member was simply marked at points on the surface of the globe. The circumscribed area on the surface of the globe, corresponding with a solid angle originating at the globe center, described a bounding surface within which the moving part was unhindered. This shape has been called the excursion cone of the joint ${ }^{25}$ or joint sinus. ${ }^{18}$

FIGURE 2 shows such globes at the principal joints of the limbs. Each globe may be regarded as fixed to one of the joint members, with the excursion cone so placed that the other member is provided with a guide or template that permits only a circumscribed amplitude of joint movement. (Except for the knee and foot, where the globe is affixed to the distal member, the proximal part of the joint at the other globes is fixed with the distal part moving within the excursion cone.) Where there are three degrees of freedom, rotations of the moving member about its own axis are possible, but the extent of this has not been specified in FIGURE 2 .

At the ball-and-socket joints, there are contingent restraints to movement at the limits of the excursion cone. When the free member is twisted on its long axis to the limit in one direction or the other, the excursion cone for the remaining degrees of freedom may be characteristically widened or narrowed at one point or another of its boundary. Conversely, as shown in FIGURE 3C, if the free member (humerus) is moved to the maximum limit of the excursion cone, the bone rotates so that its front surface comes to face in different directions. FiGURE 3C shows movement at the glenohumeral joint (three degrees of freedom). FIGURE 3B shows six degrees of freedom (glenohumeral plus claviscapular joint systems), and FTSURE 3A shows nine degrees of freedom (glenohumeral, claviscapular, and stemoclavicular). At $A$, there is no one fixed joint center; note the range of movement of the humeral head. At $B$, the humeral head likewise shuttles about. Although it is less clear at $C$, there is, as will be shown later, likewise no fixed center. This illustration underscores the complexity of shoulder movements in a way that is not clear in globographic representations by Fick, ${ }^{17}$ Braus, ${ }^{7}$ and von Lanz and Wachsmuth. ${ }^{38}$ Correct movements have been shown in this joint ${ }^{5}$ by the use of $X, Y$, and $Z$ coordinates.

The cadaver measurements referred to, although they have analytical value, are inadequate as representing living motions, and they are based on too few analyses. Measurements that have been made upon living subjects have likewise been inadequate for most joints, since they have ignored the contingent 


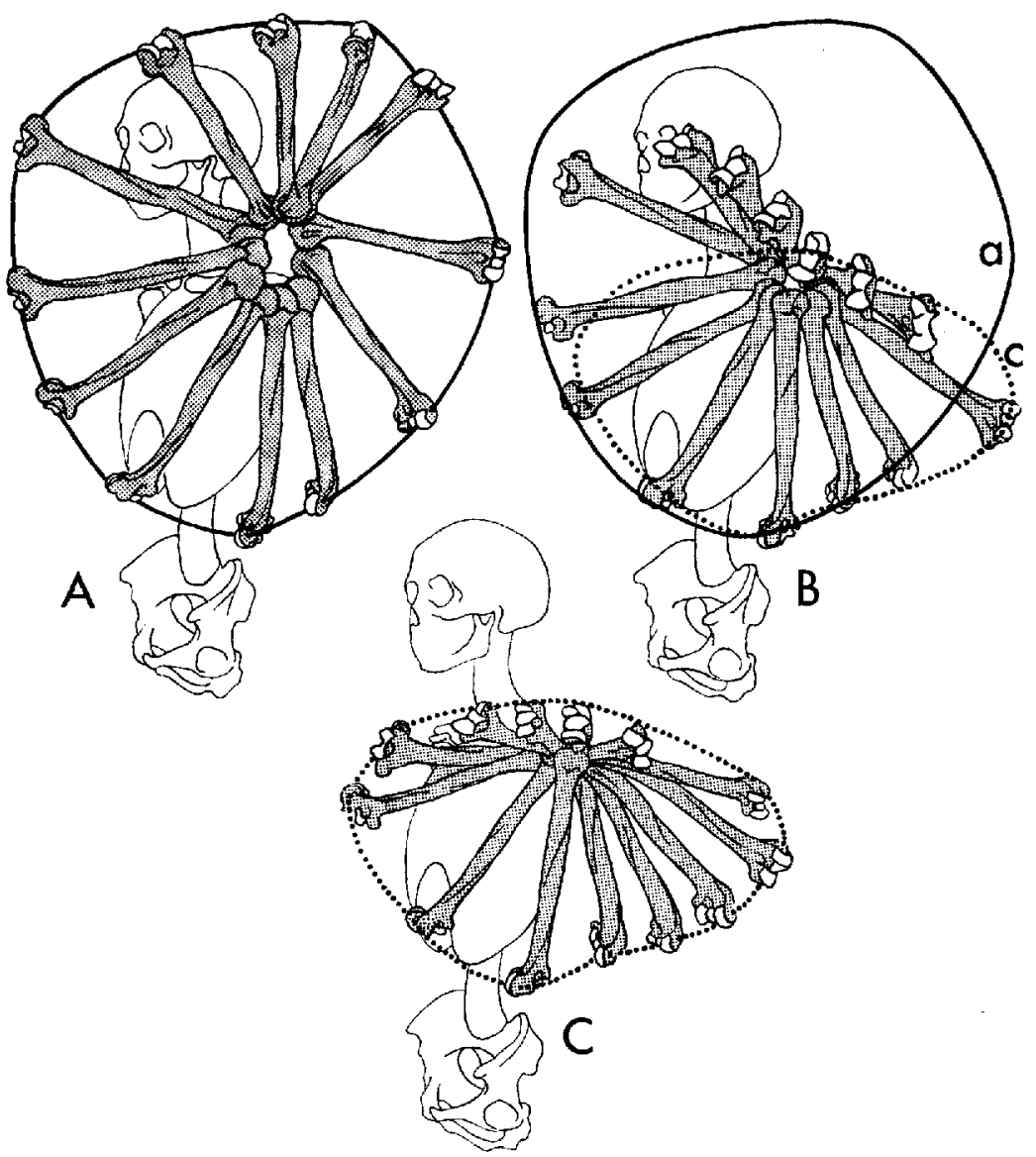

Figure 3. Range of humeral movement at the shoulder joints.

restraints and the complexity of component joint systems at certain regions (shoulder, foot, elc.). Muscular restraints also operate in the living subject. The fist, for instance, will not flex or extend at the wrist as much as the flat hand; the extent of hip bending is different if the knee is bent or straight.

There is a need for well-planned dynamic measurements of joint range (i.e., link movement) on men, women, and children and on different racial and occupational groups. The effect of training and exercise should also be of interest.

\section{The Relative Orientation of Adjaceni Joints}

Although improved information on joint range is desirable, data on isolated joints cannot entirely reflect the cumulative geometric background for body motion. It is important to know, in addition, although the point has scarcely been recognized, the relative orientation of one joint to the next in sequence.

Measurements on bones have shown variability in the inclination and dec- 
lination angles of the femoral neck relative to the femur when laid on a table with the posterior aspect of the condyles flat. The torsion angle of the humerus likewise has a variable range. ${ }^{24}$ The plane of the tables of the tibial condyles lies at different angles to the shaft axis in different specimens; the plane of the scapular blade has a variable angle to a plane across the glenoid margin; the ulnar axis has a variable angulation to the axis of elbow bending; and the clavicular axis has a variable angulation to the plane of its acromial articular facet.

These points and others based on osteological material suggest that the bony span between the joints may be more or less twisted or turned relative to the joints. The excursion cones of one joint may face inward or outward or otherwise, relative to the excursion cone of the more proximal or more distal joints. Because of this, the cumulative range of the end member of a limb may have an orientation to the trunk in one individual that is quite different from that in another. An extreme example points to the problem; if a humeral twist directed the forearm backward or outward instead of forward and inward, how different the hand action would be. Again, how different the lower limb action would be if the knee were directed outward instead of forward. The variability in angulations of the joints at the two ends of a bone should cumulatively modify the motion patterns of different individuals. This is a field for the anthropometrist interested in dynamic problems.

\section{Joint Centers in Relation to Links}

Until now, links have been regarded as axial core lines that intersect joint centers. The implication of the globographic technique is that joint centers are points or axes fixed relative to the bones. It will be shown here that joint centers have variable positions and that links in the body system do not have fixed lengths.

The German engineer, Reuleaux ${ }^{32}$ in 1875 developed a method for defining rotations in a plane in terms of instantaneous axes of rotation. The method has becn applied to the jaw ${ }^{3,9}$ and to the knee $^{39}$ in living subjects. Figure 4 shows the general method of Reuleaux. Two points in a body change their angular position as the body rotates from position $A$ to position $B$. Lines drawn from the first to the second position of the two points are shown by a dashed and a solid line. Perpendiculars from the midpoints of each line intersect at point $A B$. This is the instantaneous center that defines the average (i.e., circular) movement as the points change their angular positions. At a later moment, point $B C$ defines a new instantaneous center for the movement $B$ to $C$. In this way, a path of instantaneous centers corresponds with the whole rotation $A$ to $E$. For a scries of small angular displacements, the method gives an accurate picture of movements in a plane.

When one member of a joint preparation is rigidly fixed in a vise and the other is moved, two points on the latter change their angular relations in the same way as the points on the moving chip of FIGURF 4. Analyses of shoulder flexion and elbow flexion were combined in one illustration for FIGURE 5. For each 10 degrees of rotation of the humerus relative to the scapula (and for the ulna relative to the humerus), an instantaneous center has been shown by a black dot. In each instance, the joint centers formed a cluster of points that 
suggest erratic changes in axis positions with movement. Each of the other major limb joints shows comparable axis shiftings. Only truly reciprocal articular curvatures can be expected to slide about an axis of constant position. The diameter of the cluster was at least a half inch for the elbow (four specimens), and three-quarters inch for the shoulder (three specimens). ${ }^{11}$ Clusters for shoulder adduction were of the same general size. The specific pattern differs from specimen to specimen, but the cluster sizes are comparable for each type of joint. It is possible that muscular actions in the living shoulder would move the contacting parts of the joint even more. 'The speed of action is believed to affect cluster size also.

If the link is to be defined as the spanning distance between the centers of rotation of adjacent joints, it must change its length, of course, from moment to moment in an unpredictable way. The humeral link may vary by one and one-fourth inches or more. Certainly, a dynamic anthropometry with such variability cannot hope for the millimeter or so tolerances sought in static anthropometry.

The wrist was analyzed for joint-center location by taking a series of X-ray views with angiocardiographic equipment. Fifteen exposures for a flexion or adduction sweep were made. (The forearm was supported well, and a projecting rod from a hand grip swept over a plane surface parallel to the film; tiny lead shot imbedded in the forearm support and in the moving rod represented static and moving points.) An analysis by the Reuleaux method of the superimposed images of the shot (the black dots) showed the familiar

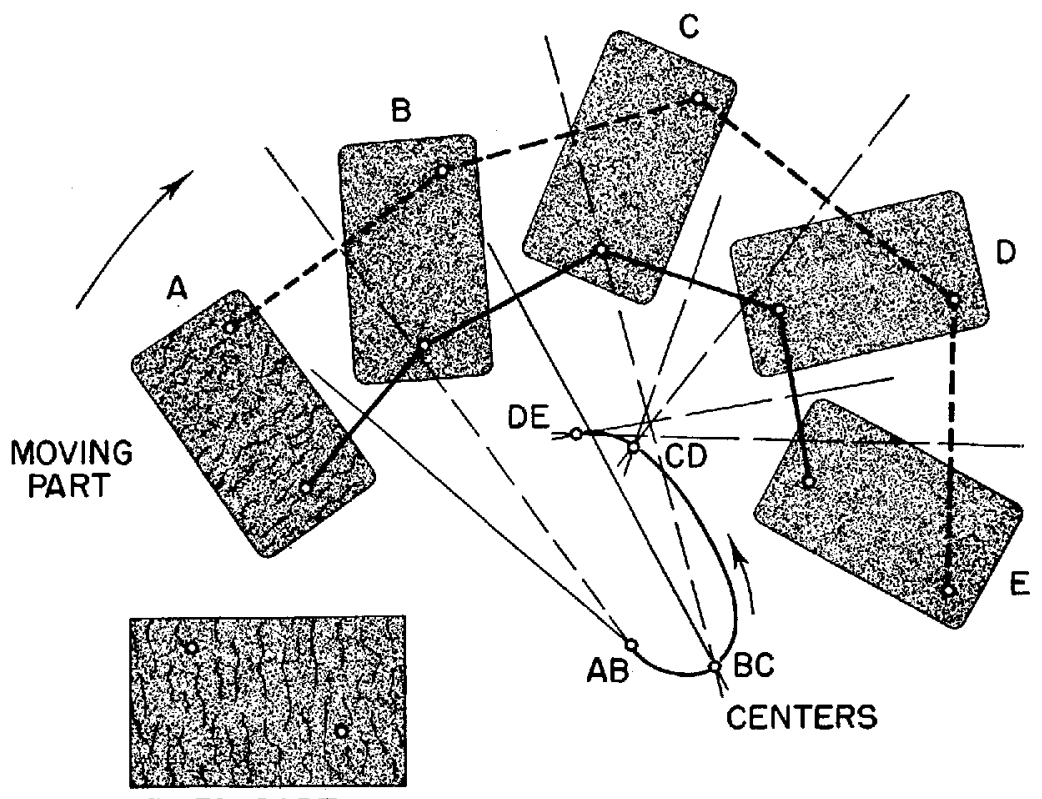

FIXED PART

FIGURR 4. Reuleaux method of locating instantaneous centers of rotation. 
cluster of instantaneous joint centers (white dots). They ranged over a threequarter inch circle in the carpus and centered over the lunate-capitate junction. Similar procedures using motion-picture records with reference points traced frame by frame showed the same type of cluster.

With a cluster at the elbow and at the wrist, the forearm link, like that of the humerus, must vary in length from moment to moment. Analyses of movement must be content with mean link dimensions and mean joint centers with an inbuilt variablity factor.

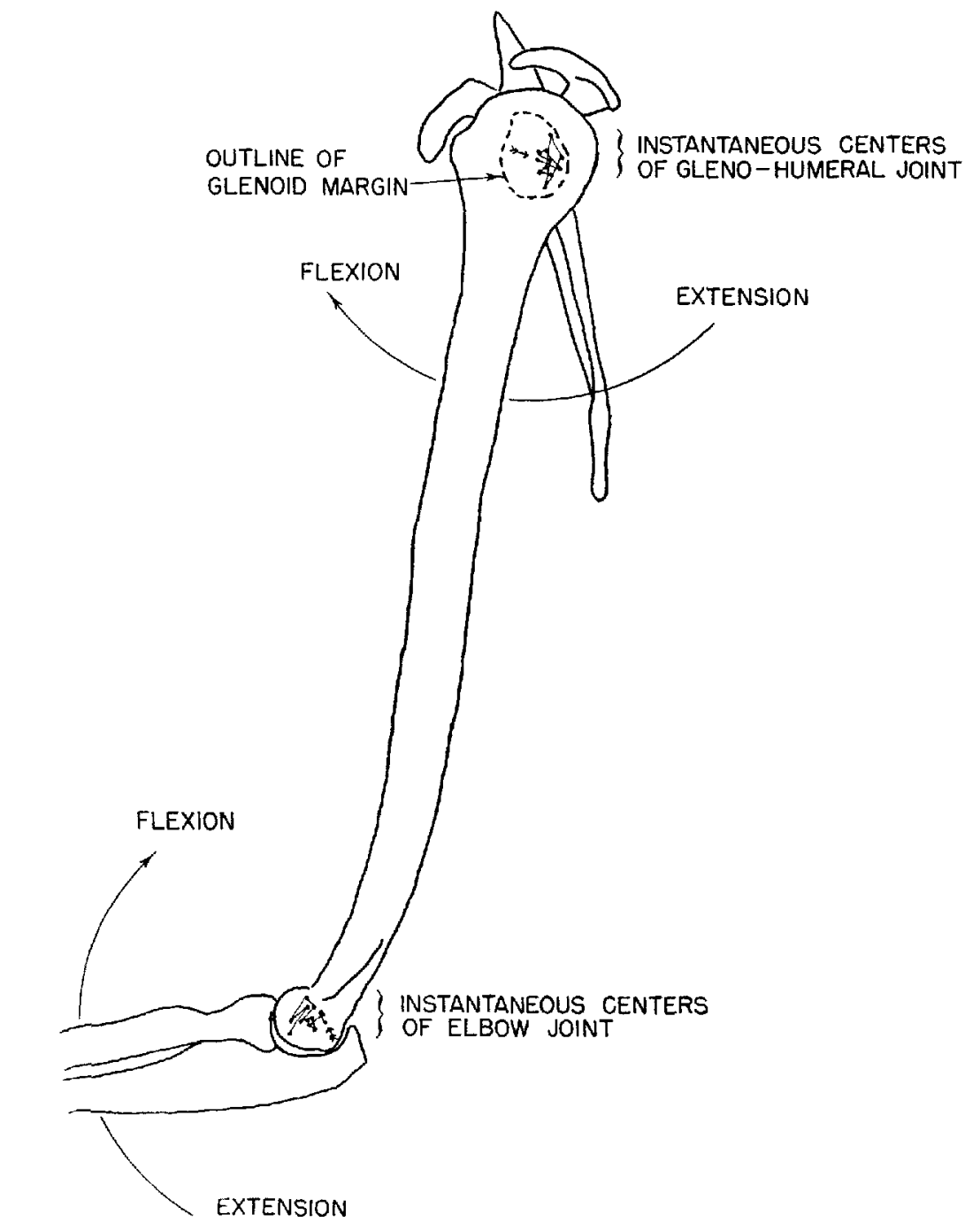

FicuRE 5. Puttern of instantaneous joint center, for flexion-extension movements at the glenohumeral and elbow joints. 


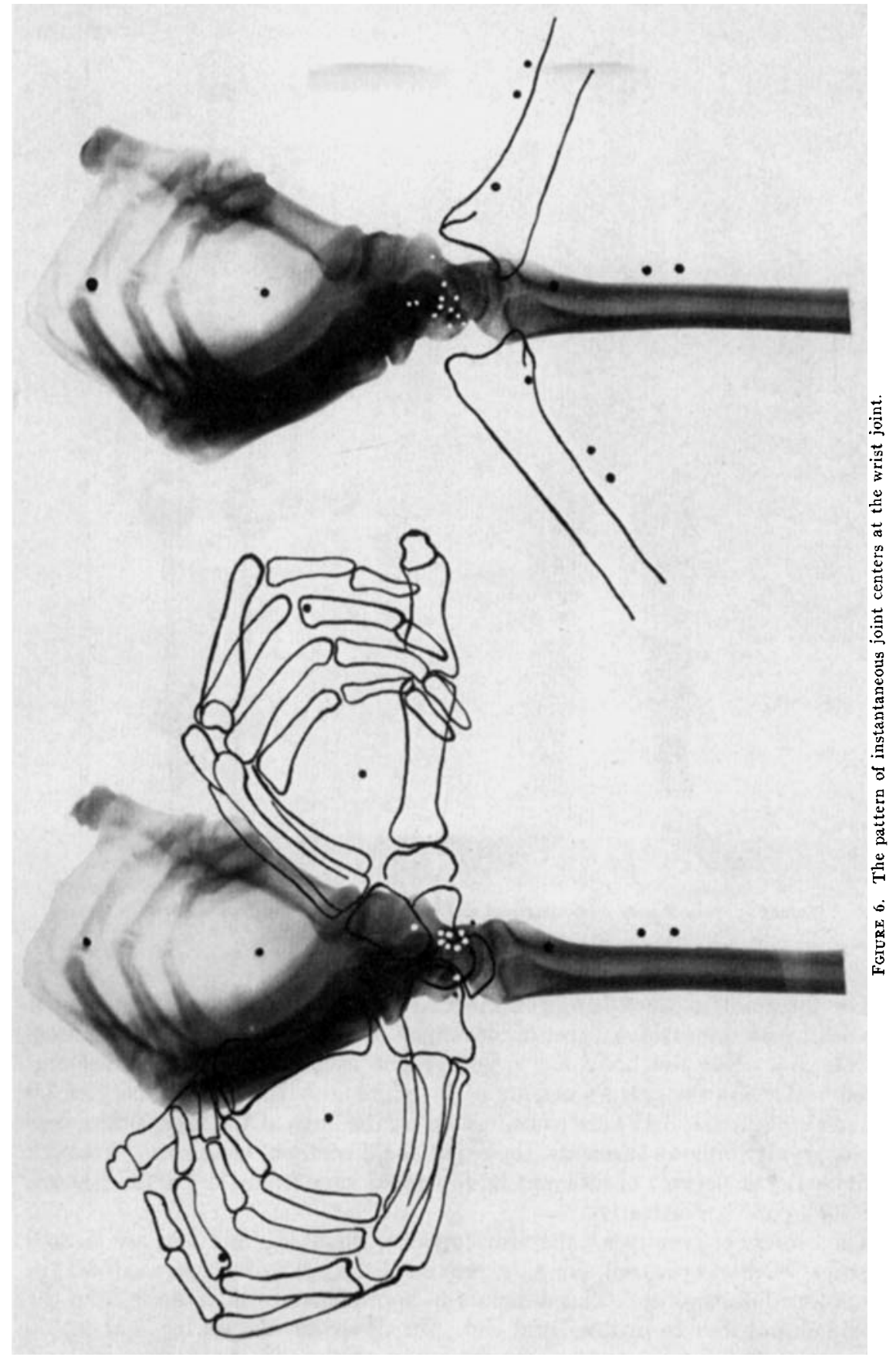




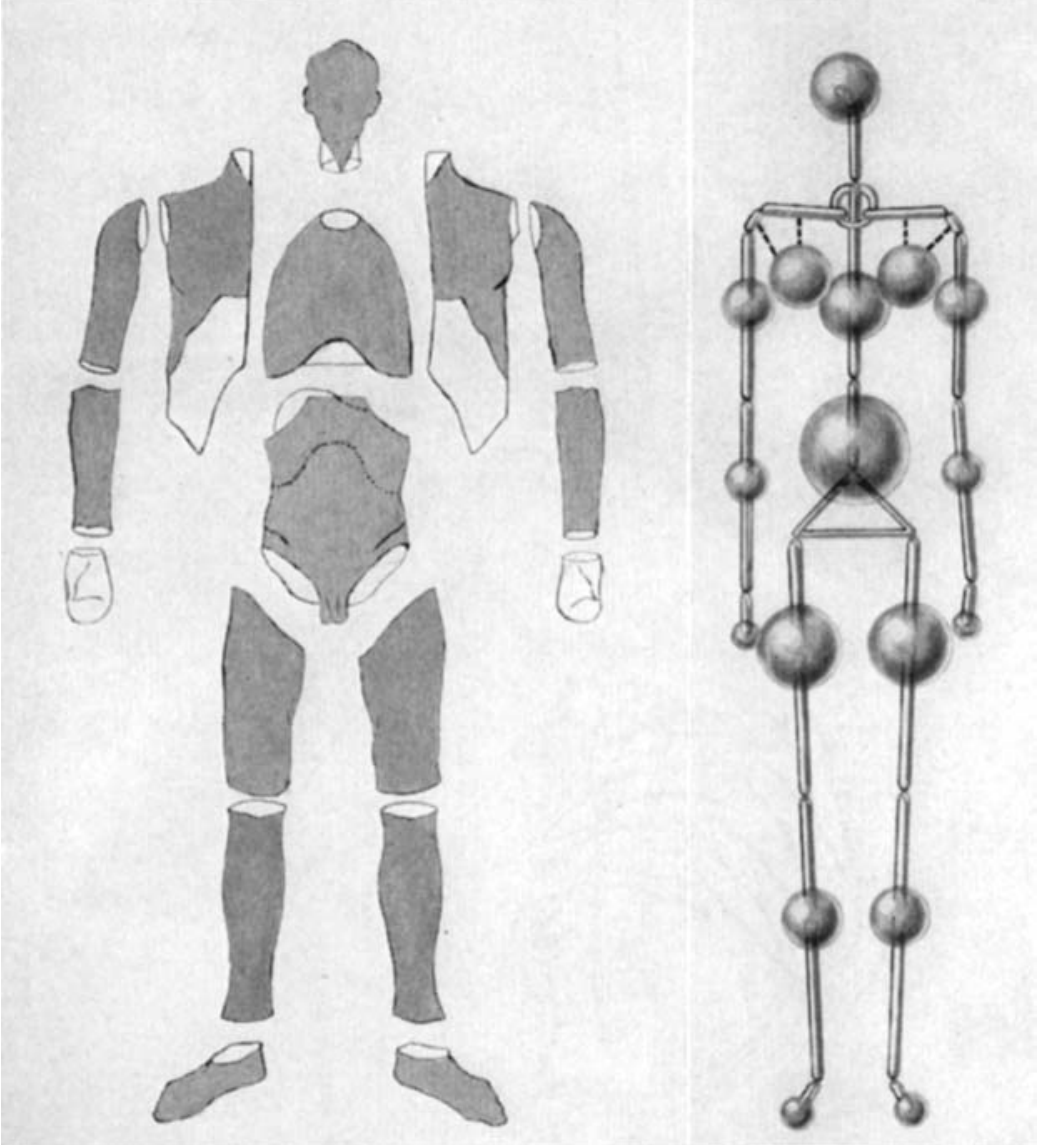

FIGURE T. Plan of body dismemberment and relative masses of the body segments.

\section{The Body Force System}

The foregoing account has been kinematic, i.e., purely geometrical, and it has dealt with dimensions, types of movement, angles, orientations, and centers of rotation. But the body has mass. Eight cadavers have been dismembered $^{11}$ following the pattern of FIGURE 7 . If metal balls with a density of 8.0 ( $c f$. steel, 7.8 ; brass, 8.4) were to be located on the links at the appropriate centers of gravity of body segments, their size would be about as shown. Younger individuals, or persons of different build, would vary from the pattern shown, but the figure is illustrative.

The centers of gravity for the arm, forearm, thigh, leg, and foot are located at points about 43 per cent along the proximodistal span of the segment length (i.e., mean link length). This amounts to approximately three units from the proximal and four from the distal end. In the hand, the center is about 50 per cent of the distance from the wrist center to the end of the member for a 
mean position of rest, but it varies with hand posture. In the trunk, exclusive of the limbs but including the head, the over-all center of gravity lies about 40 per cent of the height above the hip joints. The head center of gravity is 43 per cent of the distance from the vertex to the disk between the seventh cervical and first thoracic segments.

Gravitational pull continually acts upon the segments, and the magnitude of the forces upon the parts is proportional to their mass. The mass imparts an inertia to the segments. Muscular force is required to hold a posture against gravity, to move parts if they are at rest, or to decelerate them if they are moving. The physics of rotation applies, and the parameters for a detailed mechanical analysis involve couples, a balancing of torques, moments of inertia, angular accelerations, angular momentum, and energy relations. The textbooks of physics and mechanics, however, are only partially helpful, since the relative motions of the segments depend also upon the kinematic system outlined above. Muscles, through their often-changing leverages, are an essential part of the forces acting on the body, but mass, inertia, and environmental forces are equally involved.

The technical analysis of certain dynamic problems may be reasonably outside the domain of dynamic anthropometry. Nevertheless, the influence of mass and other forces has a continuous effect upon the man who is subject to measurement. He develops a personal style in the handling of his body segments, he fatigues, he is saving on his energy, or he may be motivated toward unusual efforts. Psychological factors involving habit, training, boredom, motivation, and frustration may influence the quality and style of performance. In other words, the test subject is human and his handling of the postures and motions of his personal open-chain link system is individualistic. The vagaries of neuromuscular control make the body quite unlike the closed-chain system of machinery.

\section{Measuring the Dynamic Individual}

Three general classes of dynamic measurement may be anticipated and the purposes of the measurement are pertinent:

(1) Any specific skilled individual performance or critical phase of such performance may be measured as an approach to understanding the mechanical nature of the activity. The individual is secondary to the specific performance. This emphasis prevails in locomotion studies, in the analysis of top-level athletic performance, in the investigation of the use of prostheses by the maimed, and in the study of skilled repetitive behavior of the sort used in industry. Perhaps measurements made with such aims are not strictly anthropometric.

(2) The defining of the over-all or potential space used by representative individuals of a population may be measured. The potential range of effective hand or foot postures may be analyzed for seated, standing, or recumbent postures, and the relative effectiveness of the different regions within reach may be compared.

(3) The variability in the dimensions, style, and performance exhibited by samples of a population may also be measured so that knowledge of the general pattern of certain purposeful operations may be known. For instance, it 
should be possible to analyze the general kinematic activity and space requirements of typists, desk workers, punch press operators, or the drivers of vehicles.

\section{Characteristics of the Skilled or Repetilive Performance}

When actions are studied from motion picture records analyzed frame by frame or from stroboscopic records, the motions are broken into a series of instantaneous stages. Students of locomotion (Bernstein, ${ }^{4}$ Elftman, ${ }^{15,16}$ Eberhart and Inman, ${ }^{13}$ Klopsteg and Wilson $\left.{ }^{23}\right)$ and analysts of the sports patterns and other activities ${ }^{10,14}$ have worked with this technique. Simultaneous or accessory records from the side, front, rear, and above or below have advantages in this work.

Figure 8 shows a representative type of record that might be analyzed in this fashion; it shows an athlete putting the shot. The record shows rhythm, sequence of postures, and a pattern of force application directed solely to the twin objectives (1) of getting a maximum distance of throw, i.e., the highest possible velocity at the moment of release for the best possible trajectory; and (2) enough body control in the follow-through phase for the performer to stay within the prescribed ring. An alternate and more carefully worked out link figure analysis would have permitted measurements of both velocity and acceleration of the travel of the shot and the angular velocities and accelerations of

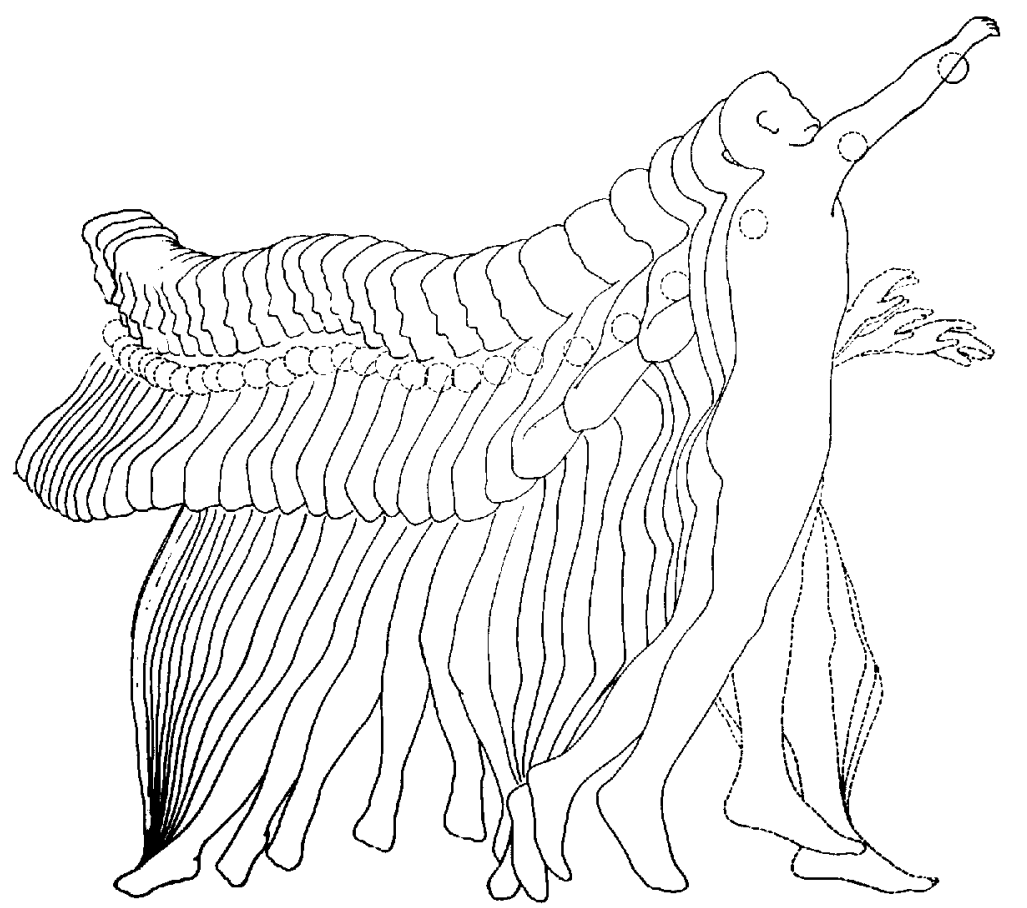

FigURE 8. Pattern of body movement in the shot put. 
the motions of the body segments. Knowledge of the moments of inertia of the body segments would contribute further to the analysis. The relative value of the fall forward, the hop, and the lunge may be stated in quantitative terms. Top-grade performance may be analyzed in comparison with throws of less distance. The strongest and the weakest phases of the performance may be contrasted, and methods for improvement may be devised.

Any critical performance is subject to this type of analysis when quantitative parameters are available. The capacity of a prosthesis-wearing amputee may be studied, and the effectiveness of tool using may be analyzed. The purpose and emphasis of the analyst will ordinarily be a search for an understanding of the factors that operate in the performance.

\section{Work-Space Problems}

Quite in contrast, the development of effective work spaces, which do not cramp large individuals nor inconvenience others by poor placement of controls, calls for studies that relate to a poplulation. The hand and foot are specialized as the utility agents of the limbs. For any position of the body, the effective reach of these parts defines the space available for potential activity. It would appear feasible, at first sight, to determine such a range of hand or foot movements with a reasonable accuracy if the link dimensions and amplitude of joint movements were known. It should be expected that the range of rotational movements at each joint in a chain of links could be combined in sequence. FIGURE 9, $A$ and $B$, points to the impracticability of such a procedure, however.

Assume that the humerus moves in the plane of the paper through an arc such as that shown at $A$. Then assume, further, that the elbow has a flexionextension range of $140^{\circ}$ and that the hand is outstretched. The sketch at $B$, which represents a compass construction based on the upper-limb link dimensions of TABLE 1, shows the range of movement of both the wrist center and the finger tips. The construction ignores the space medial or lateral to the plane of the analysis. It would be difficult to compare the ranges of different individuals, and one may doubt if given test subjects would really approximate the range as estimated.

A way out of the difficulty is suggested by the lower sketches of the figure. At $C$, a terminal point on the humerus describes an arc as the link moves in a plane about its joint center. At $D$, a point on the forearm shows both rotatory and translatory movements in the plane of the paper. If a third link (hand) is attached to the moving part and is held in a constant orientation, it too executes translatory movements as well as rotatory. For additional links (fingers), translatory movements are likewise possible relative to the trunk. More generally, in a chain of three or more links in any plane, that link which has two joints allowing compensatory movement may have translatory motion as well as rotational movement.

Both the hand and foot form such a relation to the trunk, hence motions of either end member may be measured as translatory movement in given test subjects and the ranges of movement may be grouped or compared. FIGURE 10 shows a method for analyzing the range of hand movement relative to some 


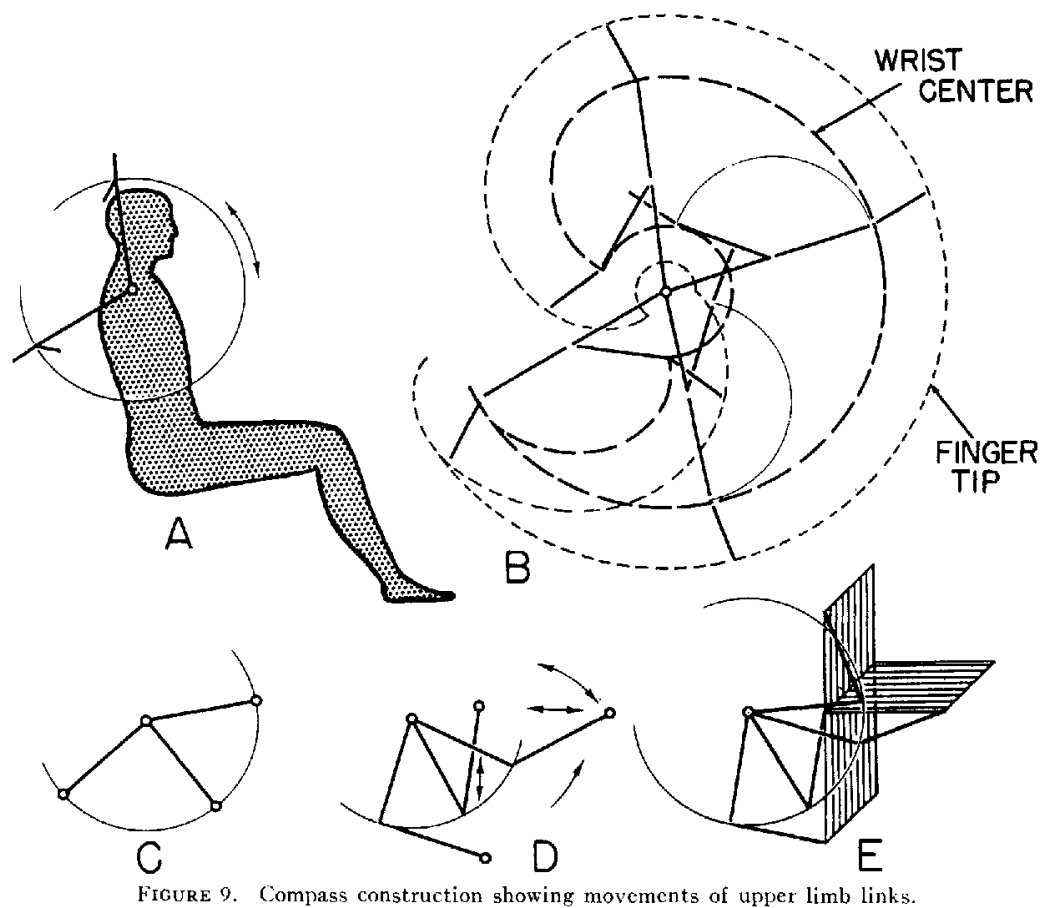

TABLE 1

Limb-Bone Lengths and Estimated Link Dimensions for a Male Build of 175 cm. $\left(5^{\prime} 9^{\prime \prime}\right)$ Stature

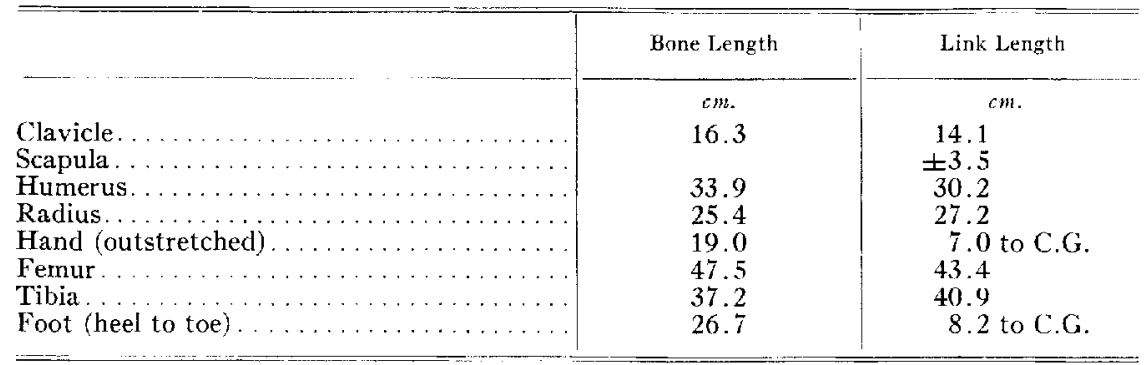

fixed reference point on the seat on which a subject sits. The subject holds a reference grid with the hand continually in a fixed orientation-prone, supine, grip vertical, etc.--and he moves the hand and grid over a plane surface, such as a wall, to the limits allowed by the cumulative joint action of the limb. In the method shown, a flashing neon glow lamp at the hand describes a path that represents the limits of extreme motion in the plane of reference (other moving lights at the elbow and shoulder are irrelevant to the central problem). The $45^{\circ}$ mirror view simply provides a check that the movement is reasonably in the plane of reference. 


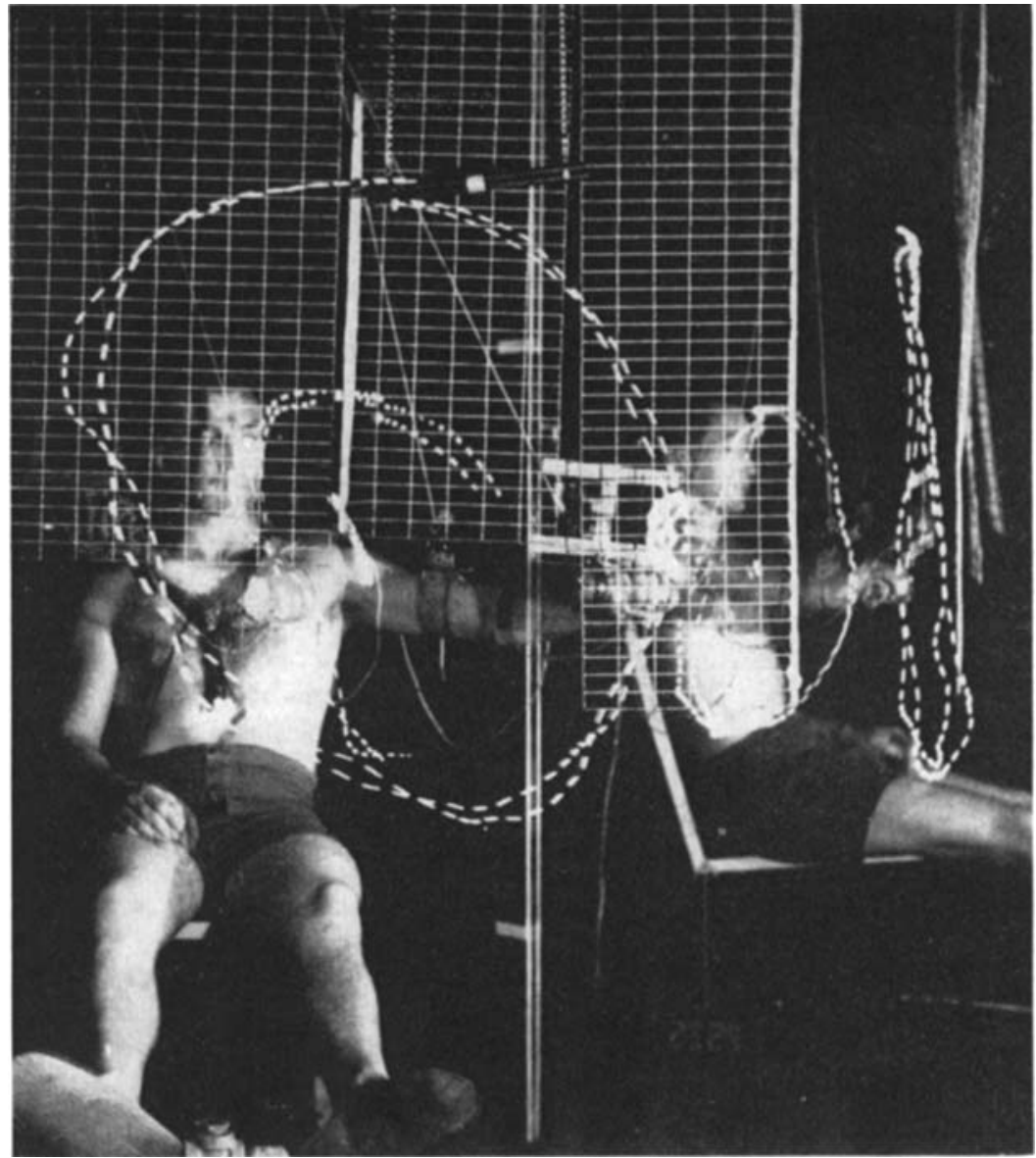

FIGURE 10. Method for recording extreme movements of the hand.

When the subject (and the seat) is moved forward a measured distance, a new record shows the range in a plane closer to the subject. Enlarged tracings of successive records, when superimposed, appear as in FIGURE 11; a reconstruction of successive records may be presented also as a three-dimensional model (FIGURE 12). The surface of the shape represents the limits of reach relative to a fixed reference point (on the seat) for the hand as held in a fixed orientation. The term "kinetosphere" has been coined for the space required by an end member (hand or foot) held in a constant orientation and moving in translation relative to some fixed reference point. ${ }^{11}$

Records (such as those shown in FIGURE 11) representing sections through a kinetosphere can be compared for different subjects. The centroid position may be calculated, and the volume may be determined from planimeter measurements of the several outlines. Perpendicular sections through the centroid in different planes (horizontal, sagittal, or transverse) may be scaled off on 
coordinate paper. These likewise may be compared directly for different end member orientations or for different individuals. Records of different individuals may be superimposed, traced, and averaged. Deviations from the average in different directions may be measured.

When the arbitrary fixed hand orientation is changed, certain limiting ligaments at one or more of the joints bind in such a way as to change the cumulative space range. Accordingly, the shape envelope differs with each hand orientation. Records of different hand orientations may be grouped in different combinations.

The kinetosphere analysis forms a valuable tool for defining the range of actual motion exhibited by subjects. The common region for all hand orientations may be defined. In contrast, regions for only special hand orientations may be located. The length of straight-line movements in any direction may be determined. The amount of right-left hand overlap may be measured for various hand orientations. Regions (centroids) that are, on the average, farthest from the limiting boundary may be located. Thus, in addition to learning the limits of reach for various hand orientations, it is possible to evaluate the space in terms of regions of variable utility to the body.

The empirical subject-by-subject study of kinetospheres is not a purely dimensional study. It deals with actual rather than ideal movements of subjects.

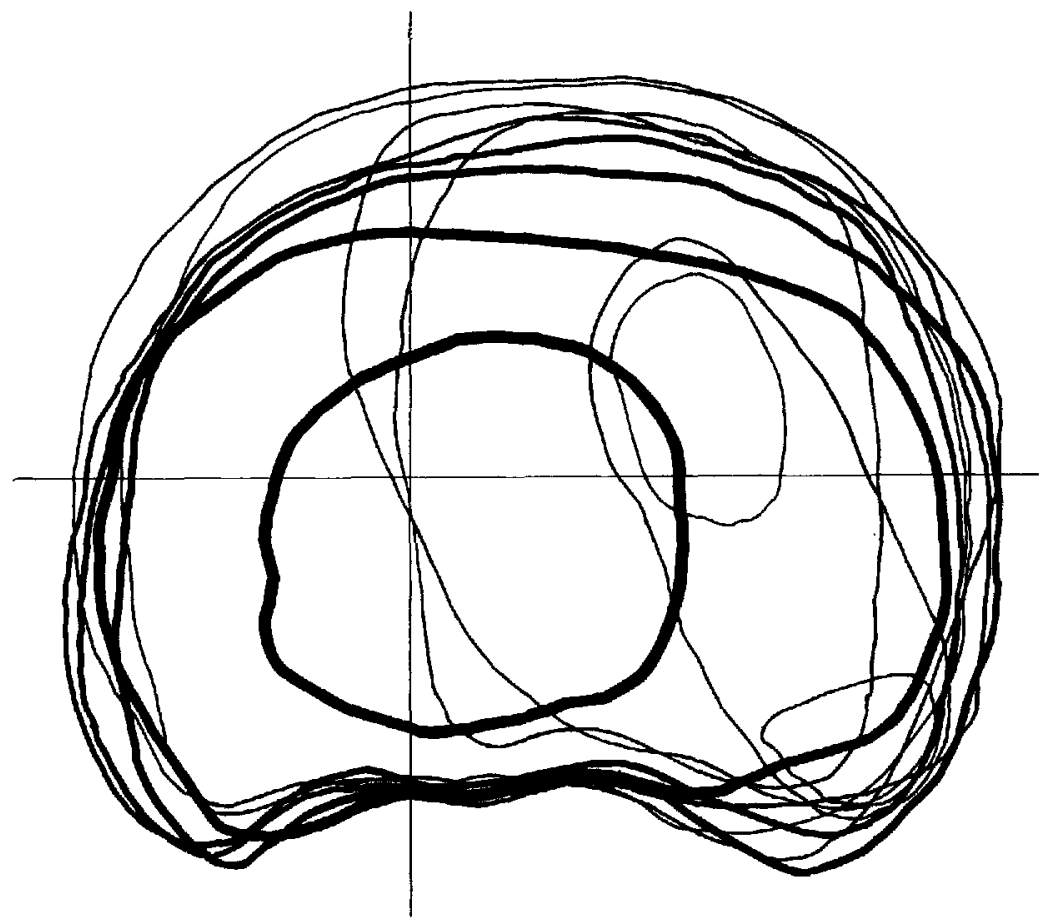

Figuke 11. Superimposed frontal-plane serial sections showing the pattern of extreme movements of the prone hand. 
Any psychological factors, such as laziness, willingness to exert to the limit, and individual limitations associated with peculiarities of the joint range and limitations due to fat or muscular restraint are to be found in the records much as they will be in actual purposeful movements within the reach of the different subjects.

Cumulative records of kinetospheres on one subject or of composites representing a group of subjects may be measured. Average volumes or linear dimensions may be determined for the space within reach. Applications to both the foot and the hand have been studied. ${ }^{11}$

\section{Variability in Purposeful Behavior}

Human activity involving tools, furniture, and equipment may be broken down for analysis into a variety of purposeful patterns - the pianist, the or-

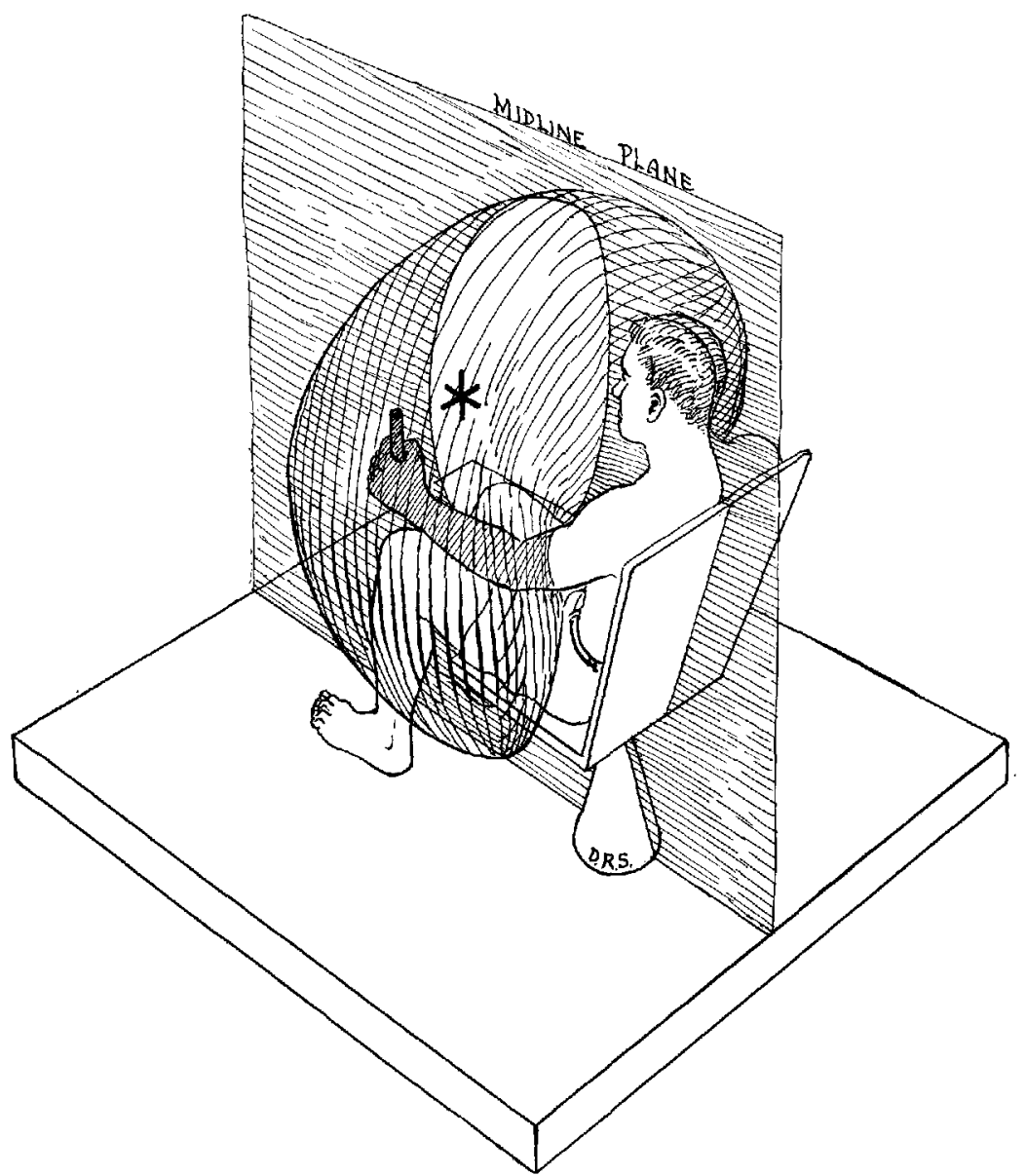

Figure 12. Sketch of a 3-dimensional model of a kinetosphere showing the range of possible movement of the hand when held with the grip vertical. 


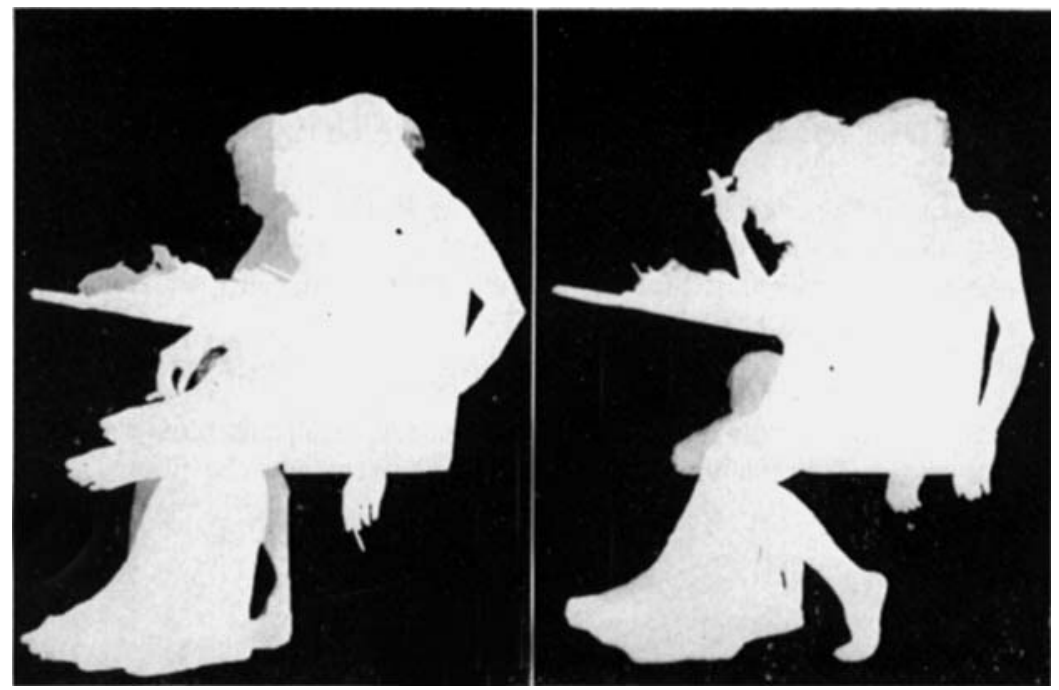

FIGURE 13. Representative phases of body posture of two subjects performing comparable desk activities.

ganist, the desk worker, the typist, the cook, the driver or passenger of a vehicle, or the operator of a machine in industry. The body patterns of such individuals may be recorded for representative phases of this activity, such as the multiple exposure records of FICURE 13 showing reading, writing, and other desk activities. Permanent records of this type may either show equal time intervals - say minute intervals - or they might be selective and show merely representative phases of a total action pattern. Such records show individual differences in the style and pattern of people accommodating their dimensions and mass to the tools and purposes of the activity. Records might be made in different planes, and different individuals or classes of activity might be comparcd. In any event, the records may be measured in terms of linear dimensions, areas, or volumes. Such measurements should pertain to furniture designing or architectural usage.

What is pertinent is that the actual variety of postures and movements be objectively studied rather than imagined. If a record of actual body patterns is available, methods for significant measurement can be devised.

\section{The Sludy Sample for Measurement}

It should be obvious that where the nature of a repetitive stereotyped activity-walking, running, athletic performance, etc-is to be studied, one should select individual representative or top-level performers. Population measurements are unimportant here. Population data are likewise unimportant if applications are to be made for one subject, or for a group of individuals of similar dimensions. There should be no problem in planning work-space facilities for a given body size. In the practical use of sizing data, a limited range of body dimensions can be fitted well, viz., clothing, furniture, workspace, 
but as the range of individual dimensions approaches that of a large population, the fit becomes less and less good.

The vehicle driver or the industrial worker who must be fitted with standard equipment, however, represents a large population that can be measured-even by static anthropometry-only through samples. This means that the dimensions of the extreme deviates in the total population cannot even be predicted. The mean, however, may be estimated with reasonable accuracy, and it is equally possible to designate individuals who would be included within plus or minus 1,2 , or 3 standard deviations, or individuals within certain percentile ranges.

Accordingly, one follows the principle of the greatest good for the greatest number. If a work space fits, for example, 90 per cent of a population reasonably well, 10 per cent (i.e., the largest and smallest) are inconvenienced to some degree, and they must compensate as best they may. No one in specific instances can define the critical percentile with assurance, but 90 to 95 per cent are reasonable tentative levels.

The labor involved in dynamic measurements precludes studies on large population groups. When a population of interest, or a reasonable equivalent, has been measured by static anthropometry, the mean values and the \pm 2 (or \pm 3 ) standard deviation level should be available. These limiting values or calculations of the 95th and 5th percentiles (including 90 per cent of the population) define individuals of critical larger and smaller dimensions. If, now, small test samples of individuals are carefully selected, with reasonable concern for tolerance limits in several dimensions (height, weight, limb dimensions, etc.) these should be fair subjects for dynamic studies. Dynamic data on samples of even 5 or 10 large, median, and small subjects, selected on the basis of static measurement should form a fair functional approximation to what would be shown by the larger group.

For each of the dynamic study groups, the performance range would vary with differences in joint movement, strength, willingness to exert, eic., as in any practical situation. Subjects of small dimension might well exceed the range of performance of some individuals in both the other groups. This approach allows the defining of average, superior, and restricted levels of performance that would be representative for the larger population. The use of highly selected groups should have pertinence in both the study of potential ranges of movement, i.e., work-space data, or in the study of special purposeful patterns of behavior involving furniture, tools, and other accouterments.

\section{Conclusions}

If a dynamic anthropometry relating to movement patterns is to be developed, it must proceed on an understanding of the nature of body kinematics and the importance of forces in relation to posture and movement. The actual movements must be studied and recorded, preferably with adequate permanent records of the motions; the purposes of the study will determine the parameters for measurement. The anthropometry may fairly relate to but one individual rather than to a population; alternately, the data may have signifi- 
cance only in relation to a population group. In the latter instance, it would appear preferable, rather than to use a random group of study subjects, to select test subjects carefully, so that they match definite dimensions in the population to which the data are to be applied. The over-all potential range of motion can be defined, or a purposeful class of behavior may be measured, when carefully selected representative individuals are studied in actual or welldesigned mock situations. Static measurements made with subjects in one posture cannot be reassembled to represent dynamic patterns. Static measurements, however, do have importance in the defining of a population for which dynamic measurements may have pertinence. They likewise provide a basis for the judicious selection of study subjects for dynamic measurements.

\section{References}

1. Âkerblom, B. 1948. Standing and Sitting Posture, with Special Reference to the Construction of Chairs. Nordiska Bokhandeln. Stockholm. Sweden.

2. At.Bert, E. 1876. Zur Mechanik des Hüftgelenkes. Med. Jahrb. k. k. Gesellsch. d. Artzte. Wien.: 107-129.

3. Bennetr, N. G. 1908. A contribution to the study of the movements of the mandible. Proc. Ruy. Soc. Med. (odont. sect.). 1(3): 79-98.

4. Bernstern, N. 1935. Lntersuchungen über die Biodynamik der Lokomotion. Bd. 1. Biodynamik des Ganges des normalen erwachsenen Mannes.; 243. Inst. Exptl. Med. Soviet Union (Moscow). (In Russian; German summary).

5. BraUne, W. \& O. Fischer. 1888. Über den Antheil, den die einzelnen Gelenke des Schultergürtels an der Beweglichkeit des menschlichen Humerus haben. Abhandl. math.-phys. KJ. königl. sächs. Gesellsch. Wiss. 14(8): 393-410.

6. BRAUne, W. \& O. Fischer. 1890 . Über den Schwerpunkt des menschlichen Körpers mit Rücksicht auf die Ausrüstung des deutschen Infanteristen. Abhandl. math.phys. Kl. königl. sächs. Gesellsch. Wiss. 15: 561-572.

7. Brads, H. 1921. Anatomie des Menschen. Bewegungsapparat. Vol. 1. Springer. Berlin, Germany.

8. Chapants, A., W. R. Garner, \& C. T. Morgnn. 1949. Applied Experimental Psychology. Wiley. New York, N. Y.

9. Chissin, C. 1906. Über die Offnungsbewegung des Unterkiefers und die Beteiligung der äusseren Pterygoidmuskeln bei derselben. Arch. Anat. u. Physiol. Anat. Abt. : $41-67$.

10. Cureton, T. K. 1939. Flementary principles and techniques of cinematographic analysis as aids in athletic research. Research Quart. Am. Assoc. Health, Phys. Ed. Rec. 10(2): 3-24.

11. Dempster, W. T. 1955. Space Requirements of the Seated Operator: Geometrical, Kinematic, and Mechanical Aspects of the Body with Special Reference to the Limbs. WADC Tech. Rept: 55-159. Wright Air Development Center, Air Research and Development Command, U. S. A. F., Wright-Patterson Air Force Base, Ohio.

12. DempstrR, W. T. \& R. T. Limdicoat. 1952. Compact bone as a non-isotropic material. Am. J. Anat. $91(3): 331-362$.

13. Hefrerhart, H. D. \& V. T. Inman. 1951. An evaluation of experimental procedures used in a fundamental study of locomotion. Ann. N. Y. Acad. Sci. 51: 1213-1228.

14. Eugerton, H. E. \& J. R. Kit.itan. 1954. Flash, Seeing the Unseen by Ultra High Speed Pholography. Branford. Boston, Mass.

15. Elfman, H. 1939. The rotation of the body in walking. Arbeitsphysiol, 10(15): $477-484$.

16. Elytman, H. 1943. On dynamics of human walking. Trans. N. Y. Acad. Sci. 6: 14.

17. FICK, R. 1911. Handbuch der Anatomie und Mechanik der Gelenke. Part 3-Speziclle Gelenk - und Muskelmechanik in Bardeleben: Handbuch der Anatomie des Menschen. 2(1). Fischer. Jena, Germany.

18. Fischer, O. 1907. Kinematik organischer Gelenke. Vieweg \& Sohn. Braunschweig. Germany.

19. Glanville, A. D. \& G. Kreezer. 1937. The maximum amplitude and velocity of joint movements in normal male human adults. Human Biol, 9: 197-211.

20. Hicks, J. H. 1953. The mechanics of the foot. I. The joints. J. Anat. 87(4): 345 $35 \%$. 
21. Ноoтon, E. A. 1945. A Survey of Seating. Harvard Univ. Dept. Anthropol. Statistical Lab. Harvard Univ., Cambridge, Mass.

22. KING, B. G. 1948. Measurements of man for making machinery. J. Phys. Anthrop. 6: $341-351$.

23. Klopsteg, P. E. \& P. D. Wirson. 1954. Human Limbs and Their Substitutes. McGraw-Hill. New York, N. Y.

24. KrahL, V. E. 1947. The torsion of the humerus; its localization cause and direction in man. Am. J. Anat. 80(3): 275-319.

25. Langer, C. 1865. Lehrbuch der Anatomie des Menschen. Braumüller. Wien, Austria.

26. LAY, W. E. \& L. C. Fisher. 1940. Riding comfort and cushions. S.A.E. Journal. $47: 482-496$.

27. MCFARLAND, R. A. 1953. Human engineering. Aviation Age. 19(6): 214-219.

28. McFartand, R. A., A. Damon, H. W. Stoudt, A. L. Mostey, J. W. Dunlap \& W. A. Hall. 1953. Human Body Size and Capabilities in the Design and Operation of Vehicular Equipment. Harvard School Public Health. Boston, Mass.

29. Mollier, S. 1938. Plastische Anatomie: Die konstruktive Form des menschlichen Körpers. 2nd ed. Bergmann. Müchen, Germany.

30. Pruhl, W. 1934. Der Bewegungsumfang im Schultergelenk und der Anteil des subacromialen Nebengelenks an den Schultergelenkhewegungen. Morphol. Jahrb. 74: $670-696$.

31. Randall, F. E., A. Damon, E. S. Benson \& D. I. Patt. 1946. Human Body Size in Military Aircraft and Personal Equipment. Tech. Rep. No. 6601. Air Material Command, U. S. A. F.

32. Reuleaux, F. 1875. Theoretische Kinematik: Grundzüge einer Theorie des Maschinenwesens. Vieweg \& Sohn. Braunschweig, Germany. Also translated by A. B. W. Kennedy; F. Reuleadx, 1876. The Kinematics of Machinery: Outline of a Theory of Machines. Macmillan. London, England.

33. Rubin, G., P. Von Trebra \& K. V. Smith. 1952. Dimensional analysis of motions: III. Complexity of movement patterns. J. Appl. Psychol. 36(4): 272-276.

34. SHIINo, K. 1913. Über die Bewegungen im Schultergelenk und die Arbeitsleistung der Schultermuskeln. Arch. Anat. u. Physiol. Anat. Abt. Suppl.: 1-88.

35. Sinelnikofr, E. \& M. Grigorowitscir. 1931. Die Bewegligkeit der Gelenke als sekundäres geschlectliches und konstitutionelles Merkmal. Z. Konstitutionslehre. 15(6): 679-693.

36. Steindler, A. 1935. Mechanics of Normal and Pathological Locomotion in Man. Thomas. Springfield, Ill.

37. Strasser, H. \& A. Gassmann. 1893. Hülfsmittel und Normen zur Bestimmung und Veranschaulichung der Stellungen, Bewegungen und Kraftwirkungen am Kugelgelenk, insbesondere am Hüft- und Schultergelenke des Menschen. Anat. Hefte. 2(6/7): 389-434.

38. Von Lanz, T. \& W. Wachsmutr. 1938. Praktische Anatomie, ein Lehr- und Hilfsbuch der anatomischen Grundlagen ärztlichen Handelns. Springer. Berlin, Germany. $1(3) ; 1(4)$

39. ZuPPINGER, H. 1904. Die aktive Flexion im unbelasteten Kniegelenk. Habilitationsschrift vorgelegt der Hohen Med. Fak. zu Zürich. : 3-64. Bergmann. Wiesbaden, Germany. 